\title{
Anthropometric Analysis of Facial Foramina in Korean Population: A Three-Dimensional Computed Tomographic Study
}

\author{
Jung-Soo Lim, \\ Kyung-Hee Min, \\ Jong-Hun Lee, \\ Hye-Kyung Lee, \\ Sung-Hee Hong \\ Department of Plastic and Reconstructive \\ Surgery, Eulji General Hospital, Eulji \\ University School of Medicine, Seoul, Korea
}

No potential conflict of interest relevant to this article was reported.

\begin{abstract}
Background: Position of the facial foramina is important for regional block and for various maxillofacial surgical procedures. In this study, we report on anthropometry and morphology of these foramina using three-dimensional computed tomography (3D-CT) data. Methods: A retrospective review was performed for all patients who have undergone 3D-CT scan of the facial skeleton for reasons other than fracture or deformity of the facial skeleton. Anthropometry of the supraorbital, infraorbital, and mental foramina (SOF, IOF, MF) were described in relation to facial midline, inferior orbital margin, and inferior mandibular margin (FM, IOM, IMM). This data was analyzed according to sex and age. Additionally, infraorbital and mental foramen were classified into 5 positions based on the anatomic relationships to the nearest perpendicular dentition.

Results: The review identified 137 patients meeting study criteria. Supraorbital foramina was more often in the shape of a foramen $(62 \%)$ than that of a notch $(38 \%)$. The supraorbital, infraorbital, and mental foramina were located $33.7 \mathrm{~mm}, 37.1 \mathrm{~mm}$, and $33.7 \mathrm{~mm}$ away from the midline. The mean vertical distance between IOF and IOM was $13.4 \mathrm{~mm}$. The mean distance between MF and IMM was $21.0 \mathrm{~mm}$. The IOF and MF most commonly coincided with upper and lower second premolar dentition, respectively. Between the sex, the distance between MF and IMM was significantly higher for males than for female. In a correlation analysis, SOF-FM, IOF-FM and MF-FM values were significantly increased with age, but IOF-IOM values were significantly decreased with age.

Conclusion: In the current study, we have reported anthropometric data concerning facial foramina in the Korean population, using a large-scale data analysis of threedimensional computed tomography of facial skeletons. The correlations made respect to patient sex and age will provide help to operating surgeons when considering nerve blocks and periosteal dissections around the facial foramina.
\end{abstract}

Keywords: Facial bones / Anthropometry / Facial injuries

\section{INTRODUCTION}

The three major sensory nerves of the face are supraorbital, in-

\footnotetext{
Correspondence: Kyung Hee Min
}

Department of Plastic and Reconstructive Surgery, Eulji General Hospital, Eulji University School of Medicine, 68 Hangeulbiseong-ro, Nowon-gu, Seoul 01830, Korea E-mail: mkh797@hanmail.net

*This article had presented at 72th Congress of the Korean Society of Plastic and Reconstructive Surgeons on November 7-9, 2014 in Seoul, Korea.

Received August 30, 2015/Revised October 5, 2015 / Accepted December 3, 2015 fraorbital and mental nerve. Originating from the trigeminal ganglion in the skull base, nerve fibers supplying these travel through the facial skeleton and exit via the respective foramen. Hence, the location of each foramen is an important consideration in facial bone fracture, cosmetic surgery, and regional nerve block.

Previously, the location of facial foramina has been studied using dry cadaveric bones [1-3], photographs of dry bones [4], and radiographs limited to simple X-ray [5]. In this study, we report on anthropometry and morphology of these foramina using three- 
dimensional computed tomography (3D-CT) data. In order to obtain clinically meaningful data, various anthropometric measurements were compared according to sex and age. In addition, relationships between foramina and dentition were examined for significant association.

\section{METHODS}

This retrospective study included all patients who had undergone 3D facial CT studies between January 2008 and March 2014 at a university hospital. Patients were excluded for congenital deformity of the face and for history of a fracture in maxilla, frontal, mandible, or orbital bone. Patients with history of nasal bone fracture or soft-tissue contusion were not excluded.

Two multidetector CT machines were used for facial bone scans (Light Speed Ultra 16 and Discovery CT750 HD, General Electric, Milwaukee, WI, USA). Each image slice was obtained at $0.625-\mathrm{mm}$ thickness, which provides higher axial resolution than the usual image thickness used for 2D scanning $(1.25 \mathrm{~mm})$.

Each patient's facial CT reconstruction was loaded into a PACS station.

The largest supraorbital exit on the 3D-CT image was labeled as the foramen/notch and used for subsequent measurements. Distances were measured between supraorbital foramen (SOF) and facial midline (FM), infraorbital foramen (IOF) and FM, IOF and inferior orbital margin (IOM), mental foramen (MF) and FM, $\mathrm{MF}$ and inferior mandibular margin (IMM). Each distance was measured in the geometric central of each foramen or notch (Table 1, Fig. 1) [1].

Each distances were measured twice, and the average of the two values were used for comparisons. Statistical analyses included cross tabulation, independent T-test, and one-way analysis of variance (SPSS ver. 22.0, SPSS Inc., Armonk, NY, USA).

\section{RESULTS}

The retrospective review identified 137 patients who met the inclusion criteria (76 male and 61 female). The mean age was 36.5 years (range, 18 to 78 years) (Table 2 ).
Table 1. Definitions used for anthropometry

\begin{tabular}{|c|c|}
\hline Measurements & Definition \\
\hline SOF-FM & Distance from supraorbital foramen to facial midline \\
\hline IOF-IOM & Distance from infraorbital foramen to inferior orbital margin \\
\hline IOF-FM & Distance from infraorbital foramen to facial midline \\
\hline $\begin{array}{l}\text { IOF position } \\
\text { (in relation } \\
\text { to maxillary } \\
\text { teeth) }\end{array}$ & $\begin{array}{l}\text { Position 1: superior to the 1st premolar. } \\
\text { Position 2: between the 1st and 2nd premolar. } \\
\text { Position 3: superior to the 2nd premolar. } \\
\text { Position4: between the 2nd premolar and the 1st molar. } \\
\text { Position 5: superior to the 1st molar. }\end{array}$ \\
\hline MF-FM & Distance from mental foramen to facial midline \\
\hline MF-IMM & $\begin{array}{l}\text { Distance from mental foramen to inferior mandibular } \\
\text { margin }\end{array}$ \\
\hline $\begin{array}{l}\text { MF position } \\
\text { (in relation to } \\
\text { mandibular } \\
\text { teeth) }\end{array}$ & $\begin{array}{l}\text { Position 1: inferior to the 1st premolar. } \\
\text { Position 2: between the 1st and 2nd premolar. } \\
\text { Position 3: inferior to the 2nd premolar. } \\
\text { Position 4: between the 2nd premolar and the 1st molar. } \\
\text { Position 5: inferior to the 1st molar. }\end{array}$ \\
\hline
\end{tabular}

SOF, supraorbital foramen; FM, facial midline; IOF, infraorbital foramen; IOM, inferior orbital margin; MF, mental foramen; IMM, inferior mandibular margin.
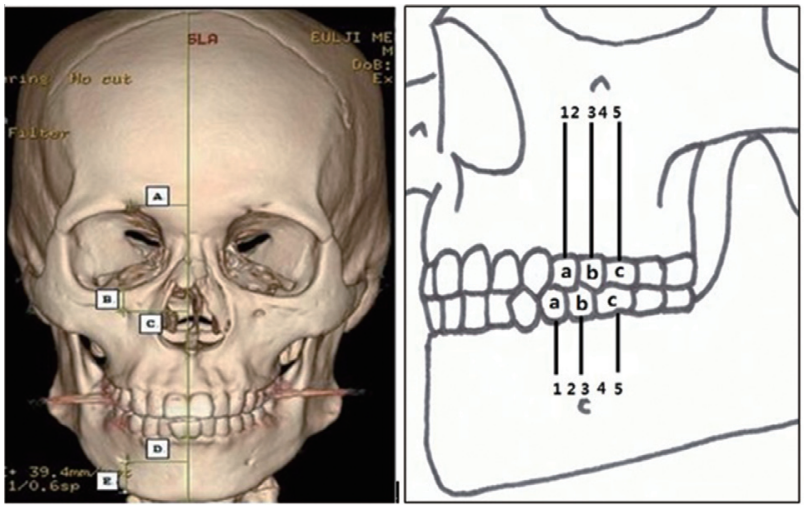

Fig. 1. Anthropometric measurements on computed tomography scan. (A) SOF-FM, distance from supraorbital foramen (or notch) to facial midline. (B) IOF-IOM, distance from infraorbital foramen to inferior orbital margin. (C) IOF-FM, distance from infraorbital foramen to facial midline. (D) MF-FM, distance from mental foramen to facial midline. (E) MF-IMM, distance from mental foramen to inferior mandibular margin. a, first premolar; b, second premolar; c, first molar; Position 1, superior (or inferior) to the first premolar; Position 2 , between the first and second premolar; Position 3, superior (or inferior) to the second premolar; Position 4, between the second premolar and first molar; Position 5, superior (or inferior) to the first molar; SOF, supraorbital foramen; FM, facial midline; IOF, infraorbital foramen; IOM, inferior orbital margin; MF, mental foramen; IMM, inferior mandibular margin.

Supraorbital exit morphology consisted of $62 \%$ foramen type and $38 \%$ notch type. For IOF position, position 3 accounted for $38 \%(104 / 274)$, the most frequent position, position 5 was $28.5 \%$ (78/274), position 4 was $16.8 \%(46 / 274)$, position 2 was $9.9 \%$ 
(27/274) and position 1 was 6.9\% (19/274) in descending order. For MF position, position 3 accounted for 40.1\% (110/274), the most frequent position, position 5 was $30.7 \%$ (84/274), position 4 was 21.5\% (59/274), position 2 was 5.5\% (15/274) and position 1 was $2.2 \%(6 / 274)$ in descending order (Fig. 2).

The average distances of SOF-FM, IOF-FM, IOF-IOM, MFFM, and MF-IMM were $33.7 \mathrm{~mm}, 37.1 \mathrm{~mm}, 13.4 \mathrm{~mm}, 33.7 \mathrm{~mm}$, and $21.0 \mathrm{~mm}$; respectively (Table 3 ).

Between male and female groups, most foraminal positions were not statistically different. One exception was that of the distance between mental foramen and inferior margin of the mandible (MF-IMM). In men, the mean MF-IMM distance was 21.7 $\mathrm{mm}$ whereas this same value was $20.1 \mathrm{~mm}$ in females $(p<0.01)$. This suggests a small but significant difference in the relationship

Table 2. Demographic information

\begin{tabular}{|cc}
\hline Category & Number $(\%)$ \\
\hline Patients & 137 \\
\hline Total sides & 274 \\
\hline Sex & \\
Male & $76(55.5)$ \\
Female & $61(44.5)$ \\
Total & $137(100)$ \\
\hline Age $(y r)$ & \\
18-29 & $57(41.6)$ \\
$30-49$ & $50(36.5)$ \\
$50-65$ & $24(17.5)$ \\
$>66$ & $6(4.4)$ \\
Total & $137(100)$ \\
\hline
\end{tabular}

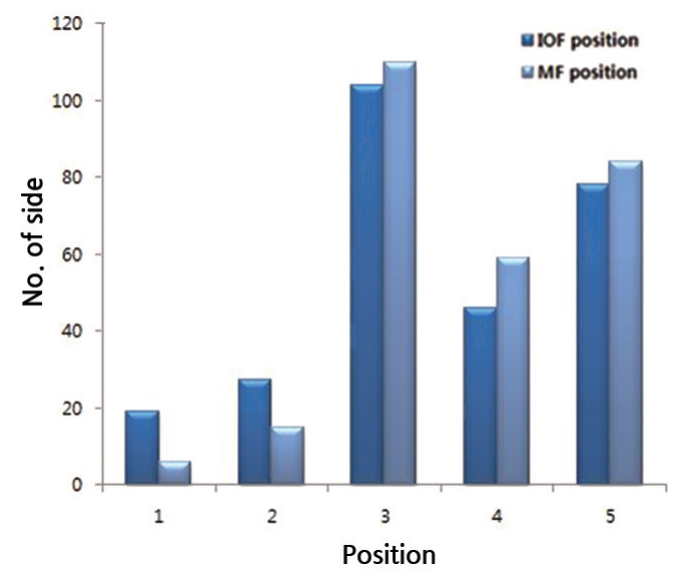

Fig. 2. The position of IOF and MF. The most frequent position was position 3 (superior (or inferior) to the second premolar). IOF, infraorbital foramen; MF, mental foramen. between the mental foramen to the inferior edge of the mandible, which places the mental foramen slightly further away from the mandibular edge.

Regarding the relationship between age and foraminal positions, all three of the foramina was further away from midline (FM) with age $(p<0.05)$. Additionally, a the distance between infraorbital foramen (IOF) and infraorbital margin (IOM) decreased with age $(p<0.001)$. The mental foramen and inferior mandibular margin (MF-IMM) distance became narrower with increasing age, but this trend was not statistically significant ( $p=0.356)$ (Table 4, Fig. 3).

Between the left and right sides, the IOF position was significantly different $(p=0.014)$. On right side, the IOF was most frequently in position 5 (33.6\%), while position 3 was the most frequent on left side (45.3\%).

\section{DISCUSSION}

Various studies have looked at anatomic positions and morphology of facial foramina of sensory nerves [1-5]. In terms of supraorbital exit morphology, Chung et al. [4] reported that supraorbital foramina (28.9\%) were less frequently observed than supraorbital

Table 3. Foraminal anthropometry

\begin{tabular}{lcc} 
Distances & Mean \pm SD $(\mathrm{mm})$ & Range $(\mathrm{mm})$ \\
\hline SOF-FM & $33.7 \pm 5.5$ & $19.6-57.7$ \\
IOF-FM & $37.1 \pm 4.1$ & $27.4-48.7$ \\
\hline IOF-IOM & $13.4 \pm 2.8$ & $7.3-20.2$ \\
MF-FM & $33.7 \pm 3.8$ & $25.2-44.8$ \\
\hline MF-IMM & $21.0 \pm 2.9$ & $15.1-29.1$ \\
\hline
\end{tabular}

SD, standard deviation; SOF, supraorbital foramen; FM, facial midline; IOF, infraorbital foramen; IOM, inferior orbital margin; MF, mental foramen; IMM, inferior mandibular margin.

Table 4. Anthropometry according to age

\begin{tabular}{lcr} 
Parameters & Pearson coefficient of correlation & $p$-value \\
\hline SOF-FM & 0.175 & 0.004 \\
IOF-FM & 0.249 & $<0.001$ \\
\hline IOF-IOM & -0.211 & $<0.001$ \\
MF-FM & 0.149 & 0.014 \\
\hline MF-IMM & -0.056 & 0.356 \\
\hline
\end{tabular}

SOF, supraorbital foramen; FM, facial midline; IOF, infraorbital foramen; IOM, inferior orbital margin; MF, mental foramen; IMM, inferior mandibular margin. 
SOF-FM (mm)

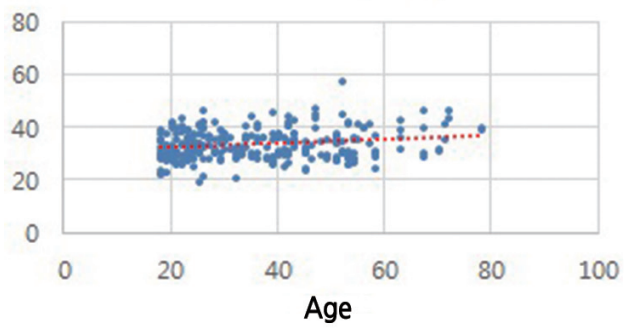

MF-FM (mm)

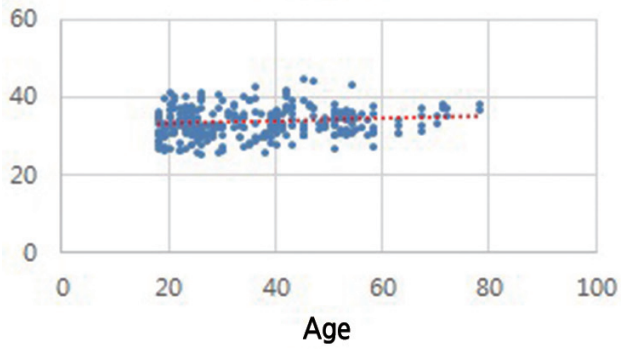

IOF-FM (mm)

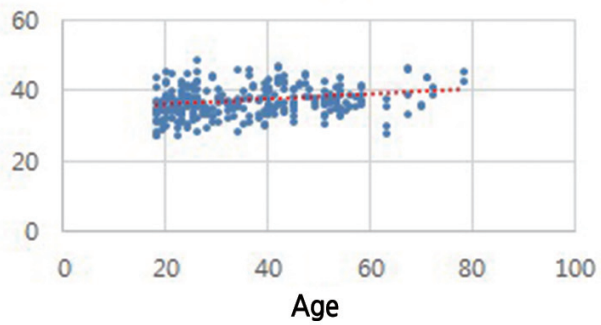

IOF-IOM (mm)

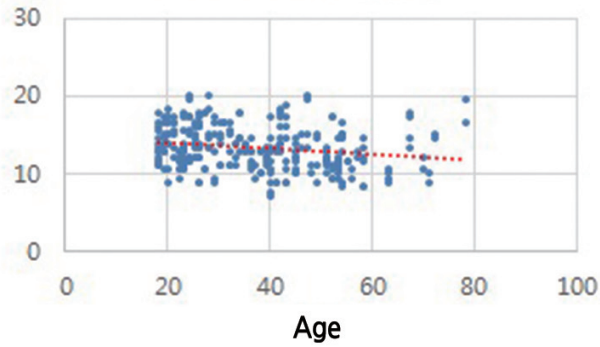

MF-IMM (mm)

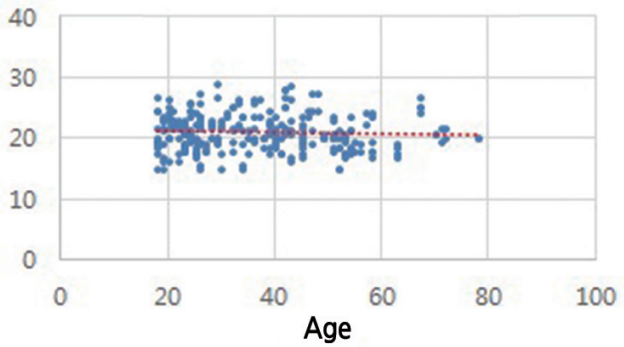

Fig. 3. Changes in the measured value in accordance with age. Distances between SOF, IOF, MF, and FM became wider as age increased ( $p<0.05)$. On the other hand, IOF-IOM distance became narrower as age increased $(p<0.001)$. MF-IMM distance became narrower as age increased, but not significantly $(p=0.356)$. SOF, supraorbital foramen; FM, facial midline; IOF, infraorbital foramen; MF, mental foramen; IOM, inferior orbital margin; IMM, inferior mandibular margin.

notches (69.9\%). Subsequent to this, Saylam et al. [6] reported similar frequencies between foramen and notch morphology $(26.6 \%$ and $71.6 \%$, respectively). Gupta [1] reported the morphological frequencies of SOF and SON as $45.6 \%$ and $54.4 \%$, respectively. In our study, however, foramen type morphology was more frequent (62\%) to notch morphology (38\%).

Gupta [1] using dry skull (North-west Indian) reported position 3 (superior or inferior to second premolar) to be the highest frequency, accounting for more than $50 \%$ of all IOF and MF positions. Similarly, we found that position 3 was the most frequent position for IOF and MF, albeit to a lesser degree (38\% and 40.1\%, respectively).

Studies on facial skeletal aging have concentrated on posterior displacement of the maxilla and shifting of the lateral and inferior orbital rim, creating a larger orbital aperture with aging. Additional studies on the lower face have revealed decreasing mandible length and height with age [7-13]. In our study, older patients demonstrated supraorbital and infraorbital foramen which were significantly further away from the midline, which suggested lateral translation of frontal and maxillary bones with aging. Also, the decreased distance between the infraorbital margin and infraorbital foramen also corresponds with the theory that the orbital aperture widens inferiorly as well as laterally. Lateral translation was also observed for mental foramen (increased MF-FM distance), which was a result that contrasts previous findings of decreasing mandibular length with aging. 
Studies on foramina position and morphology is helpful in operations such as brow-lift, blepharoplasty, and genioplasty as this information decreases the chance of inadvertent injury to the supraorbital, infraorbital, and mental nerves [14]. Also, such anthropometric data can be useful in facial bone surgery or skull base surgery. More specifically, position of the infraorbital foramen relative to midline and to lower orbital margin is important for prevent injury to the infraorbital neurovascular bundle [15]. Our study results can be helpful in Korean patients and, more generally, East Asian patients.

It is important to note that specific differences of these foramina, depending on sex and age of the patient, and this information should inform operating surgeons as they prepare for injection of local anesthetic or for periosteal dissection around the foramina.

The limitation of this study is that it did not consider variables which could affect the anthropometry, such as face size or skull size of the patient.

In addition, in this paper we have used pearson coefficient correlation analysis in accordance with age. Considering the characteristic feature of pearson coefficient, p-value may lack clinical significance despite existing statistic significance between variables.

Future studies will be needed for validation of these results.

\section{REFERENCES}

1. Gupta T. Localization of important facial foramina encountered in maxillo-facial surgery. Clin Anat 2008;21:633-40.

2. Kazkayasi M, Ergin A, Ersoy M, Bengi O, Tekdemir I, Elhan A. Certain anatomical relations and the precise morphometry of the infraorbital foramen--canal and groove: an anatomical and cephalometric study. Laryngoscope 2001;111:609-14.

3. Igbigbi PS, Lebona S. The position and dimensions of the mental foramen in adult Malawian mandibles. West Afr J Med 2005;24:184-9.

4. Chung MS, Kim HJ, Kang HS, Chung IH. Locational relationship of the supraorbital notch or foramen and infraorbital and mental foramina in Koreans. Acta Anat (Basel) 1995;154:162-6.

5. Ngeow WC, Yuzawati Y. The location of the mental foramen in a selected Malay population. J Oral Sci 2003;45:171-5.

6. Saylam C, Ozer MA, Ozek C, Gurler T. Anatomical variations of the frontal and supraorbital transcranial passages. J Craniofac Surg 2003;14:10-2.

7. Farkas JP, Pessa JE, Hubbard B, Rohrich RJ. The science and theory behind facial aging. Plast Reconstr Surg Glob Open 2013;1. http:// dx.doi.org/10.1097/GOX.0b013e31828ed1da.

8. Kahn DM, Shaw RB. Overview of current thoughts on facial volume and aging. Facial Plast Surg 2010;26:350-5.

9. Pessa JE. An algorithm of facial aging: verification of Lambros's theory by three-dimensional stereolithography, with reference to the pathogenesis of midfacial aging, scleral show, and the lateral suborbital trough deformity. Plast Reconstr Surg 2000;106:479-88.

10. Pessa JE, Desvigne LD, Lambros VS, Nimerick J, Sugunan B, Zadoo VP. Changes in ocular globe-to-orbital rim position with age: implications for aesthetic blepharoplasty of the lower eyelids. Aesthetic Plast Surg 1999;23:337-42.

11. Pessa JE, Zadoo VP, Adrian EK, Woodwards R, Garza JR. Anatomy of a "black eye": a newly described fascial system of the lower eyelid. Clin Anat 1998;11:157-61.

12. Lambros V. Observations on periorbital and midface aging. Plast Reconstr Surg 2007;120:1367-76.

13. Rohrich RJ, Pessa JE. The retaining system of the face: histologic evaluation of the septal boundaries of the subcutaneous fat compartments. Plast Reconstr Surg 2008;121:1804-9.

14. Erdogmus S, Govsa F. Anatomy of the supraorbital region and the evaluation of it for the reconstruction of facial defects. J Craniofac Surg 2007;18:104-12.

15. Aziz SR, Marchena JM, Puran A. Anatomic characteristics of the infraorbital foramen: a cadaver study. J Oral Maxillofac Surg 2000;58:992-6. 